\title{
Synthesis, Characterization and Antitumor Efficacy of Silver Nanoparticle from Agaricus bisporus Pileus, Basidiomycota
}

\author{
Mustafa Nadhim OWAID ${ }^{1,3, *}$, Ghassan Adnan NAEEM², \\ Rasim Farraj MUSLIM ${ }^{3}$ and Raheel Saeed OLEIWI ${ }^{2}$ \\ ${ }^{I}$ Department of Heet Education, General Directorate of Education in Anbar, Ministry of Education, \\ Hit, Anbar 31007, Iraq \\ ${ }^{2}$ Department of Biophysics, College of Applied Sciences, University of Anbar, Hit, Anbar 31007, Iraq \\ ${ }^{3}$ Department of Ecology, College of Applied Sciences, University of Anbar, Hit, Anbar 31007, Iraq
}

("Corresponding author's e-mail: mustafanowaid@gmail.com)

Received: 7 July 2018, Revised: 3 October 2018, Accepted: 29 November 2018

\begin{abstract}
The object of this study is to synthesize and characterize silver nanoparticles from Agaricus bisporus pileus extracts and their applications. Agaricus bisporus-mediated synthesis of AgNPs was characterized using changing the color solution, UV-Visible spectroscopy, SEM, AFM, SPM, FTIR spectrum, XRD, and EDS analyses. The change of the mixture color of $10^{-3} \mathrm{M} \mathrm{AgNO}_{3}$ with the watery extract of fresh $A$. bisporus caps from colorless to brown color is an indicator for the formation of silver nanoparticles (AgNPs). The UV-Visible spectrum exhibits the absorption peak at $418 \mathrm{~nm}$. The FTIR spectra exhibited that the structures of amino acids, polysaccharides, and polyphenols in the crude extract of $A$. bisporus are not affected because of the joining and interaction of their functional groups with silver ions, and act as reducing and capping agents to the biosynthesized Ag nanoparticles. SEM and EDS refer to the formation of AgNPs with irregular or spherical shapes. The XRD pattern exhibits face-centered cubic (fcc) silver nanocrystals, with crystalline AgNPs size of $43.9 \mathrm{~nm}$. The biosynthesized AgNPs play a suitable role against mouse cell line, which has receptors for polioviruses (L20B). After exposure of the colloid AgNPs to UV radiation $(256 \mathrm{~nm})$, the absorption band transferred from $418 \mathrm{~nm}$ to $435 \mathrm{~nm}$, indicating that UV rays affect on physical properties of AgNPs. Roughness average of the biosynthesized AgNPs from A. bisporus caps is $15.4 \mathrm{~nm}$, but the roughness is increased after UV irradiation for $1 \mathrm{~h}$ to average $33.6 \mathrm{~nm}$. Histograms of particle size distribution of AgNPs show the average of AgNPs is 103.57 $\mathrm{nm}$, while the size of nanoparticles reaches $69.47 \mathrm{~nm}$ after exposure to UV radiation of $256 \mathrm{~nm}$. The use of UV radiation leads to enhanced characteristics of silver nanoparticles.
\end{abstract}

Keywords: AFM, anticancer activity, EDS, nanomedicine, ultra violet, XRD

\section{Introduction}

Nanotechnology is an exciting recent science for interactions with sizes of particles ranging from 1 to 100 nanometers [1]. The products of nanotechnology have been used in the health and agricultural fields [2], with more applications in health and medical care increasing around the world [3]. The biosynthesis of metal nanoparticles using biomolecules plays an interesting role as reducers, stabilizers, and capping agents for element ions. These biomolecules are considered as greener agents in the Nanosciences, or so-called Green Chemistry [4].

Silver nanoparticles have been synthesized from plants [5], algae [6] molds [7], bacteria [8], and earthworms [9]. In the last 15 years, eco-friendly metallic nanoparticles have been biosynthesized from different mushrooms, such silver nanoparticles (AgNPs), gold nanoparticles (AuNPs), SeNPs, FeNPs, 
http://wjst.wu.ac.th

ZnSNPs, and PdNPs, from genera of Pleurotus, Agaricus, Schizophyllum, Ganoderma, Coriolus, Volvariella, and others [10].

Agaricus bisporus is called white button mushroom [11] and has the highest production globally [12]. Interest in the cultivation of this mushroom is increasing due to its nutritional and medical properties. It is composed from high contents of amino acids, proteins, carbohydrates, fibers, vitamins, micro and macro elements, and unsaturated fatty acids [13,14]. A. bisporus has anticancer, antioxidant, antihyperlipidemic, antidiabetic, antibacterial, antifungal, and anticandidal activities [11]. More than 53 $\%$ of the studies of mycosynthesis of nanoparticles from mushrooms are from entire basidiocarps (fruiting bodies) [10]. A. bisporus has been used to biosynthesize metallic nanoparticles such as AgNPs [15], SeNPs, SiNPs, GeNPs [16], gold nanoparticles, and cubic ZnS nanoparticles [17], but has not yet been applied as an anticancer agent.

The subject of this investigation deals in mycosynthesizing silver nanoparticles from pileus/caps of Agaricus bisporus mushrooms for the first time, due to few studies having been conducted using fractions of mushroom fruiting bodies. The biosynthesized AgNPs were characterized and tested against L20B cell cultures (mouse cells have receptors for polioviruses), and then the AgNPs were exposed to $256 \mathrm{~nm}$ ultraviolet radiation for one hour to study their influence on the size and accumulation of the formed nanoparticles.

\section{Materials and methods}

\section{Samples of the mushroom}

Fresh Agaricus bisporus fruiting bodies (or so-called white button mushroom) were purchased from the Iraq local market in Hit, which had been obtained from SHA Company Farm, Sulaymaniyah, KGRIraq, on 24 October 2017.

\section{The extraction method of $\boldsymbol{A}$. bisporus caps}

The fresh fruiting bodies were cleaned from compost residues and weighed after removing the stipes and taking only pilei (cap-like structures), as in Figure 1. The pilei were sliced into small pieces and then extracted. About $20 \mathrm{~g}$ of the sliced pilei of $A$. bisporus was extracted in $100 \mathrm{~mL} \mathrm{DW}$ using a magnetic stirrer hot plate until boiling for $10 \mathrm{~min}$, and then cooled to room temperature $\left(25^{\circ} \mathrm{C}\right)$. The aqueous extract was filtered using gauze, then centrifuged at $4000 \mathrm{cycle} / \mathrm{min}$ for $10 \mathrm{~min}$. The supernatant was collected and considered as a stock solution. The residue was emitted. FTIR spectrum of the crude extract was achieved to characterize and to compare with AgNPs which were formed later.

\section{Biosynthesis of silver nanoparticles}

About $0.169 \mathrm{~g}$ of $\mathrm{AgNO}_{3}$ (AFCO for Metal, China, with purity of $99.9 \%$ ) was dissolved in 1000 $\mathrm{mL} \mathrm{DW}$ on a magnetic stirrer until the completion was observed. The final concentration of $\mathrm{AgNO}_{3}$ solution was $10^{-3} \mathrm{M}$. Series of mushroom extract concentrations were applied $(20,40,60,80,100 \%)$. Five milliliters of $10^{-3} \mathrm{M} \mathrm{AgNO}_{3}$ solution was mixed with $5 \mathrm{~mL}$ of each mushroom concentration and kept in dark conditions at $25{ }^{\circ} \mathrm{C}$ for 3 days [18]. Additionally, $3 \mathrm{~mL}$ of $100 \%$ mushroom concentration was added drop by drop into $10 \mathrm{~mL}$ of the $\mathrm{AgNO}_{3}$ solution on a magnetic stirrer hotplate at $65-70{ }^{\circ} \mathrm{C}$ for $60 \mathrm{~min}$. The change in the mixture color was checked and recorded every $15 \mathrm{~min}$.

\section{Characterization of AgNPs}

Agaricus bisporus-mediated synthesis of AgNPs was characterized using changing of the solution color, UV-Visible spectroscopy (by spectroscopy: EMC-LAB V-1100 Digital, 325 - 1000 nm, Germany), FTIR spectrum, EDS, XRD, SEM, AFM, and SPM analyses.

\section{Effect of Ultraviolet Irradiation on the colloid AgNPs}

The biosynthesized colloid AgNPs was subjected to $256 \mathrm{~nm}$ ultraviolet (UV) irradiation for $60 \mathrm{~min}$ at room temperature in the static case inside hood. The temperature of the colloid was observed during the exposure and did not exceed $25{ }^{\circ} \mathrm{C}$. The silver nanoparticles pre- and post-ultraviolet irradiation was 
stored at $4{ }^{\circ} \mathrm{C}$. After that, changes in the color, UV-Vis, AFM, and SPM were checked and recorded to compare with the AgNPs colloid without exposure to ultraviolet radiation.

\section{Antitumor activity}

The antitumor efficacy of AgNPs toward L20B tumor cell line was investigated. The colorimetric cell viability MTT assay was used as mentioned by $[19,20]$. About $100 \mu 1 /$ well of $10^{6}$ cell $/ \mathrm{mL} \mathrm{L20B} \mathrm{cells}$ were cultured in a 96-well tissue culture plate. Three concentrations of colloid AgNPs and the extract of mushroom $(50,75$, and $100 \%$ ) were individually applied in this experiment. Then, $100 \mu 1$ of each concentration was added within each well and incubated at $37{ }^{\circ} \mathrm{C}$ for $48 \mathrm{~h}$. After that, $10 \mu \mathrm{l}$ of MTT solution $(5 \mathrm{mg} / \mathrm{mL})$ was added to each well and re-incubated at the previous temperature for $4 \mathrm{~h}$. Finally, $50 \mu \mathrm{l}$ DMSO (dimethyl sulfoxide) was added to each well and incubated for $10 \mathrm{~min}$. L20B cells were cultured in complete medium without solutions of the current test as a control. The absorbance was measured for all wells at $620 \mathrm{~nm}$ using an ELISA reader. The percent of the growth inhibition (GI) was calculated according to Eq. (1) below;

GI $\%=\frac{\text { (Optical Density of the control }- \text { Optical Density of the treatment })}{\text { Optical Density of the control }} \times 100$.

\section{Statistical analysis}

The experimental design was applied with triplications. Two factor effects of AgNPs, and the crude extract of mushroom caps were significant $(p<0.01)$ and were subjected to study the effect of this treatment toward the growth of L20B tumor cell line in vitro. The statistical analysis was applied by oneway analysis of variance using Completely Randomized Design (CRD) by SAS software.

\section{Results and discussion}

\section{Characterization of silver nanoparticles}

Change in color and UV-Visible of the biosynthesized AgNPs

The change in color of the reaction solution from brilliant yellow to brown color was seen after 60 min from the start of the reaction. AgNPs showed brown color in the reaction mixture, which is an unmistakable sign of the formation of AgNPs. This density of color increased with time due to excitation of surface plasmon vibrations in metallic nanoparticles [21] and affirmed by UV-visible spectroscopy. Absorbance intensity of brown color increased consistently as a function of reaction time. Figure 1 shows UV-visible spectrum recorded as absorbance versus reaction time during the synthesis of AgNPs from $10^{-}$ ${ }^{3} \mathrm{M} \mathrm{AgNO}_{3}$ solution and aqueous extract of Agaricus bisporus pileus mixture. It was seen that the peak relating to SPR (surface 77lasmon resonance) took place at $418 \mathrm{~nm}$, which indicated the synthesis of AgNP in the reaction solution [18]. 


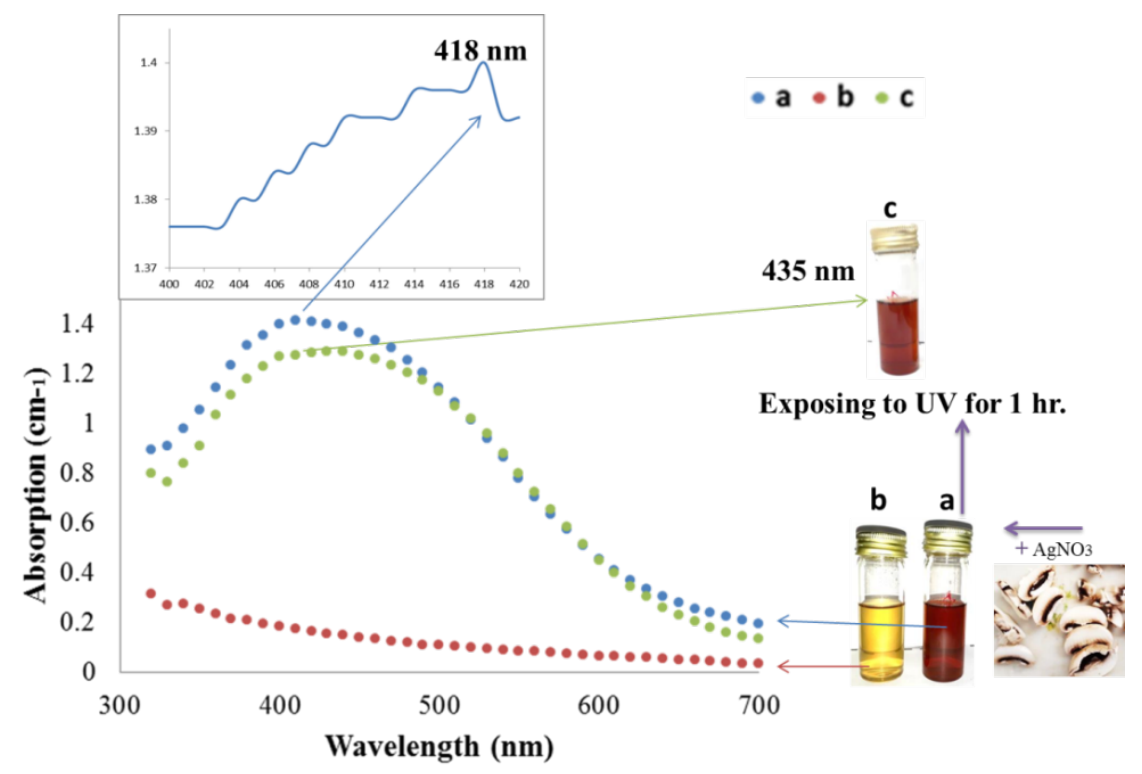

Figure 1 UV-Visible spectra of the mushroom extract and AgNPs from A. bisporus cap extract

\section{SPM and AFM of silver nanoparticles}

The colloid AgNPs were exposed to ultra-violet (UV) $256 \mathrm{~nm}$ in the hood for $1 \mathrm{~h}$ at $25^{\circ} \mathrm{C}$. The band transferred from 418 to $435 \mathrm{~nm}$, as shown in Figure 1, which indicated that UV rays affected the physical properties of the AgNPs. The irradiation clearly affected the optical, particles size, and cumulation properties of silver nanoparticles prepared from the aqueous extract of white button mushroom caps. The effect of ultraviolet irradiation was studied through the UV-visible spectrum, atomic force microscopy (AFM), and SPM. The appearance of Surface Plasmon Resonance was transferred from $418 \mathrm{~nm}$ in pre-irradiation to $435 \mathrm{~nm}$ in post-irradiation, which indicates the presence of silver nanoparticles in small sizes. However, the absorption showed a reduction in absorbance from 1412 to $1288 \mathrm{~cm}^{-1}$, indicating declining nano-scale particles and cumulation of some nanoparticles to be visible (above nano-scale) (Figures 1 and 2). This agrees with [22], which mentioned that the absorbance decreases with decrease in size for limited particle sizes. In addition to this, the irradiation transferred the peak from $418 \mathrm{~nm}$ to $435 \mathrm{~nm}$, which indicates that more particles were declining in its diameters and, thus, the rays enhanced characteristics of silver nanoparticles. The reduction in the optical band may correspond to the increased conjugation in the colloid as an effect of the embedding of silver nanoparticles becoming opaque. The precipitation of the cumulative nanoparticles leads to enhancement of the properties of the colloid solution. Roughness average of the biosynthesized AgNPs from $A$. bisporus caps was $15.4 \mathrm{~nm}$, but the roughness was increased after UV irradiation for $1 \mathrm{~h}$ to average 33.6 $\mathrm{nm}$ (Figures 2A and 2B). 


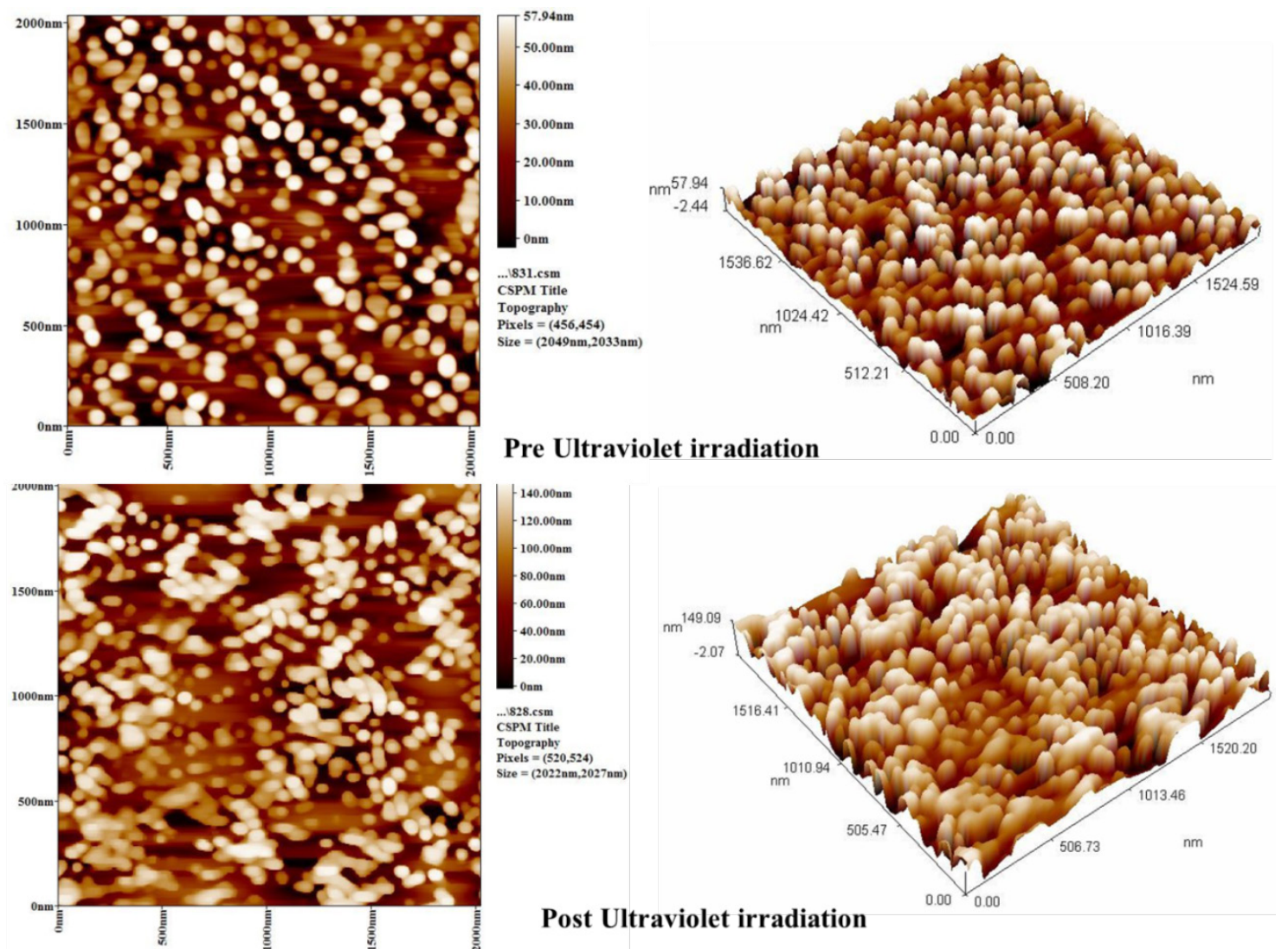

Figure 2 AFM of biosynthesized silver nanoparticles pre- and post-UV irradiation for $1 \mathrm{~h}$ at $25^{\circ} \mathrm{C}$; left images are lateral (2D), and right images are 3-dimensional (3D)

\section{Histogram of particle size distribution of silver nanoparticles}

Figure 3A shows that the average of AgNPs is $103.57 \mathrm{~nm}$, while Figure 3B shows the size of nanoparticles reaches $69.47 \mathrm{~nm}$ after exposure to UV. The reason for this is that the irritation by UV destroyed the AgNPs and increased the conjugation in the colloid solution as an effect of embedding onto silver nanoparticles and becoming opaque. Large AgNPs will accumulate and small ones will increase in the colloid, while the accumulative particles will precipitate in the bottom and it transfers to an opaque state [23]. The precipitation of the cumulative nanoparticles leads to enhancement of the properties of the colloid solution [22]. Thus, Figure 4 shows cumulation of $74.79 \%$ before UV irradiation, and decrease to $45.03 \%$ after exposure to UV, which reduced to $39.79 \%$. The irradiation leads to change compatibility and integrity of the size and morphology of the silver nanoparticles; this approach is used to sterilize the colloids of nanoparticles [24] with high stability because of the role of biogenic matters of mushroom as stabilizing agents. 


\section{http://wjst.wu.ac.th}

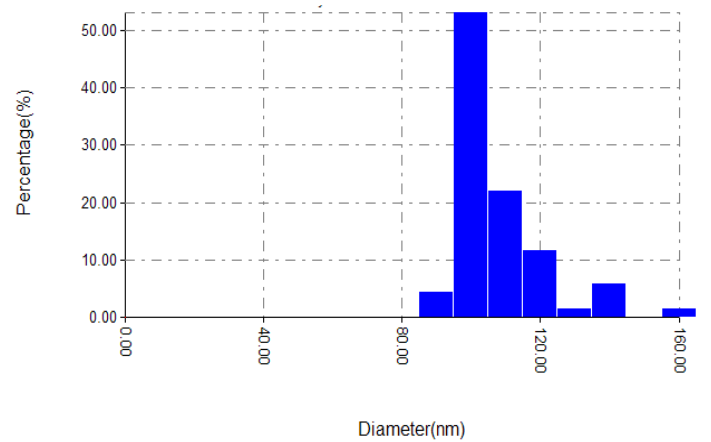

(A)

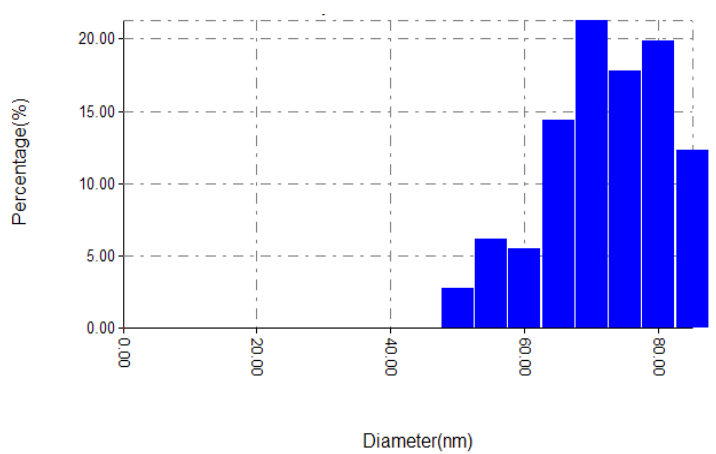

(B)

Figure 3 Histograms of particle size distribution of AgNPs (A) and AgNPs colloid after exposure to UV rays for $1 \mathrm{~h}(\mathrm{~B})$

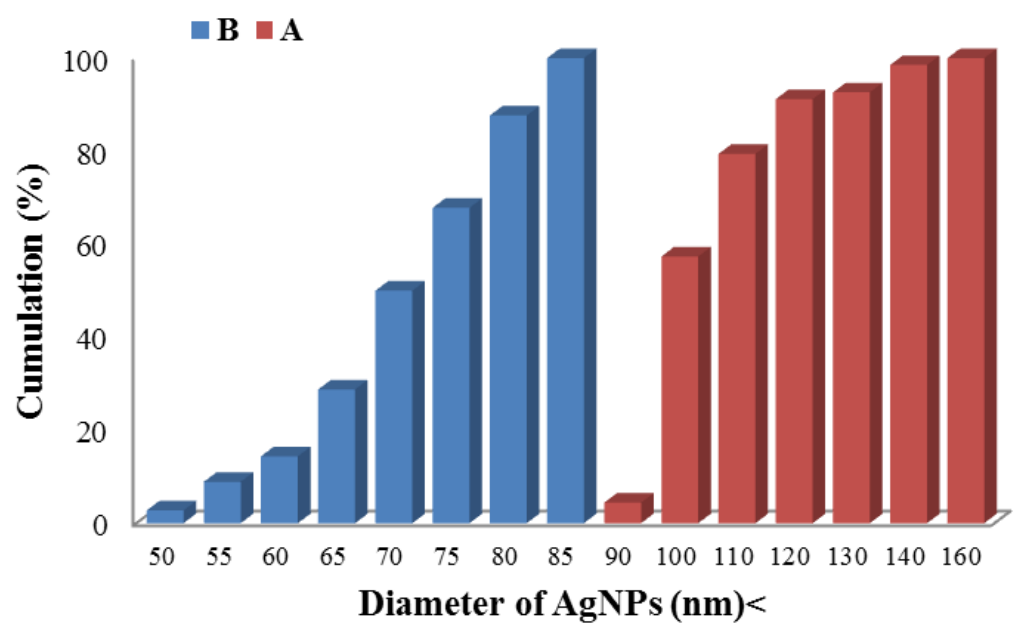

Figure 4 Granularity Cumulation distributions of colloid AgNPs

\section{FTIR of the extract and its $A g N P s$}

FTIR was used to detect the chemical composition and functional groups present in biomolecules from the crude extract of Agaricus bisporus caps and their silver nanoparticles. Figure 5A is IR of the mushroom extract, showing 2 absorption bands located at approximately 1369 and $1456 \mathrm{~cm}^{-1}$, and 2 absorption bands at 2939 and $2945 \mathrm{~cm}^{-1}$ returning to homogeneous and heterogeneous vibrations of the group - $\mathrm{CH}$. The 4 bands above refer to alkane compounds, such as methyl $\left(-\mathrm{CH}_{3}\right)$ and methylene $\left(-\mathrm{CH}_{2}\right)$, in the composition of monosaccharides, oligosaccharides, and polysaccharides, and in the composition of amino acids, proteins, fatty acids, and lipids. The previous illustration is evidenced by the presence of an absorption peak of $1039 \mathrm{~cm}^{-1}$ belonging to the single bond (C-C). The spectrum also shows a peak located at $1514 \mathrm{~cm}^{-1}$ and another peak at $1631 \mathrm{~cm}^{-1}$ belonging to $\mathrm{C}=\mathrm{C}$ group present in the composition of unsaturated fatty acids and the successive double bonds of the benzene ring in the aromatic compounds. The previous is also evidenced by the existence of a peak at $3213 \mathrm{~cm}^{-1}$ related to a stretching vibration of the group $=\mathrm{C}-\mathrm{H}$ in alkene compounds in the fatty acid composition. The spectrum also showed the presence of an absorption peak at $1317 \mathrm{~cm}^{-1}$ belonging to the methylene $\left(-\mathrm{CH}_{2}\right)$ group in the compositions of lipids. The peak at $2680 \mathrm{~cm}^{-1}$ showed the presence of hydrogen linked to the carbonyl group in the 
aldehyde $(\mathrm{O}=\mathrm{C}-\mathrm{H})$ group, and this is a sign of the presence of non-cyclic monosaccharides. The indicator of the presence of hydroxyl $(-\mathrm{OH})$ groups in amino acids and proteins containing this group is the extension vibration of the absorbent band at $3448 \mathrm{~cm}^{-1}$ and the appearance of a band of curvature at 1234 $\mathrm{cm}^{-1}$.

The absorption peak at $1456 \mathrm{~cm}^{-1}$ due to the curvature vibration of the group $-\mathrm{OH}$ and the band at $1163 \mathrm{~cm}^{-1}$ due to the extension vibration of group $\mathrm{C}-\mathrm{O}$ confirm the presence of polyphenols and melanin in the composition of the mushroom extract. The absorption peak at $2325 \mathrm{~cm}^{-1}$ belongs to the group -SH in the composition of amino acids and proteins. The 2 peaks at 549 and $648 \mathrm{~cm}^{-1}$ indicate the presence of the amide group $(\mathrm{O}=\mathrm{C}-\mathrm{N}-\mathrm{H})$ which links successive 2 amino acids in the composition of peptides and proteins. The peak at $1570 \mathrm{~cm}^{-1}$ belongs to $\mathrm{C}=\mathrm{N}$ group, and this is a sign of resonance in the amide (-NH) group as a result of its transfer to ${ }^{-} \mathrm{O}-\mathrm{C}=\mathrm{N}^{+}-\mathrm{H}$, and the band at $3483 \mathrm{~cm}^{-1}$ also belongs to the amide group $(-\mathrm{NH})$. The bands at 3406 and $3448 \mathrm{~cm}^{-1}$ respectively belong to the bending vibration and extension vibration for the amine group $\left(-\mathrm{NH}_{2}\right)$ found in the composition of amino acids and proteins. The band at $1542 \mathrm{~cm}^{-1}$ also indicates the presence of the group (-C-N) found in the composition of amino acids and proteins $[25,26]$.

The evidence for the presence of a carboxylic group (-OOH) in fatty acids, lipids, amino acids, proteins, and melanin are the elasticity of vibration band at $3510 \mathrm{~cm}^{-1}$ and a curvature vibration band at $882 \mathrm{~cm}^{-1}$ belonging to the hydroxyl group in the carboxylic group. The presence of the broad absorption peak $2500-3610 \mathrm{~cm}^{-1}$ and carbonyl group $(\mathrm{C}=\mathrm{O})$ at $1640 \mathrm{~cm}^{-1}$ are also an indicator for the presence of a carboxylic group [27-30]. The spectrum showed that there were 2 bands, 781 and $1108 \mathrm{~cm}^{-1}$, which is considered evidence of carbon-oxygen binding in the mushroom constituents of the silicon element. The first band is due to $\mathrm{Si}-\mathrm{C}$ group, and the second one is due to $\mathrm{Si}-\mathrm{O}$ group [26].

In Figure 5B, the sharp absorbent peak at $1016 \mathrm{~cm}^{-1}$ and the 2 clear bands at $1380 \mathrm{~cm}^{-1}$ and 1461 $\mathrm{cm}^{-1}$ and the clear wideband at $1623 \mathrm{~cm}^{-1}$ are clear evidence of the presence of silver nanostructures in the composition of the biosynthesized silver nanoparticles [31]. The spectrum of silver nanoparticles (Figure 5B) was observed to be similar regarding the sites of the functional groups, but the appearance of the bands was more apparent and better. This may be due to the presence of silver atoms with a high surface area, which allows all the atoms with negative charge and containing pairs of electrons not involved as in the mushroom extract to participate well in the silver nanoparticle sample containing the atoms of silver spread. It is known that silver atoms contain 47 electrons, so contained in its fifth shell is one electron in the second level $5 \mathrm{~s}$. Thus the other secondary levels are $5 \mathrm{p}$ containing 3 orbitals, $5 \mathrm{~d}$ containing 5 orbitals, and 5 f containing 7 empty orbitals, so can accommodate electronic pairs coming from atoms with good negative charge. These atoms are $\mathrm{O}, \mathrm{N}$, and $\mathrm{S}$, found in the compositions of monosaccharides, oligosaccharides, polysaccharides, amino acids, proteins, fatty acids, lipids, melanin, and polyphenols. These compounds were found to be the main compounds in the composition of the mushroom, which coordinated with empty orbitals in the formation of silver nanoparticles. The active groups obtained the freedom to vibrate and are not affected by the negative atoms of oxygen, nitrogen, and sulfur, because their electronic pairs are busy in harmony with the empty orbitals in the composition of the silver atoms and, thus, appear in good and clear stretches. The 2 FTIR spectra mainly showed that the structures of proteins, amino acids, and polyphenols in the crude extract of $A$. bisporus are not affected, because of their joining and interactions with ions of silver, and act as the reducing and capping agents to the biosynthesized Ag nanoparticles. 

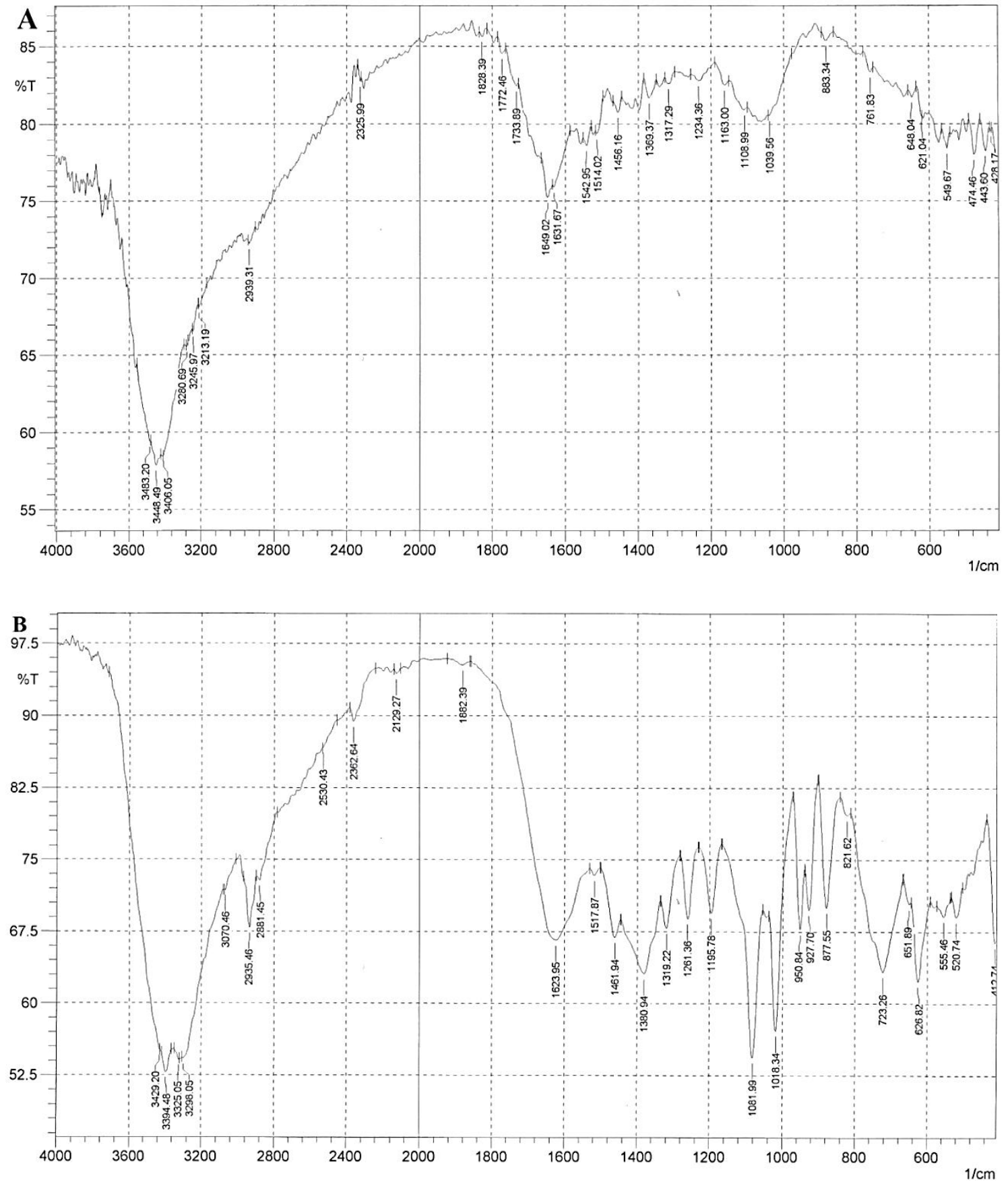

Figure 5 FTIR of the biosynthesized silver nanoparticles (A: extract of mushroom, B: AgNPs) 
http://wjst.wu.ac.th

\section{EDS and SEM images of AgNPs formed from mushroom extract}

Figure 6 exhibits the SEM image of Agaricus bisporus-AgNPs, which seems to be composed of irregular particles. The EDS spectrum of the biosynthesized AgNPs shows the silver element (3.57\%) as an indicator for the formation of silver nanoparticles from A. bisporus cap extract. Also, it exhibits that the $\mathrm{C}, \mathrm{O}, \mathrm{Cl}$, and $\mathrm{K}$ elements are present in the used sample. Carbon and oxygen are presented in this sample due to the organic molecules which are found in the extract of the mushroom. These biomolecules may be amino acids or proteins or polysaccharides or polyphenols, which capped the silver nanoparticles as capping and stabilizing agents. The presence of the elemental Ag can be seen in the EDS spectrum (Figure 7), which proves the reduction of $\mathrm{Ag}$ ions to the element Ag. Further, chlorine is observed due to the unreacted precursors of $\mathrm{AgNO}_{3}$ [32].

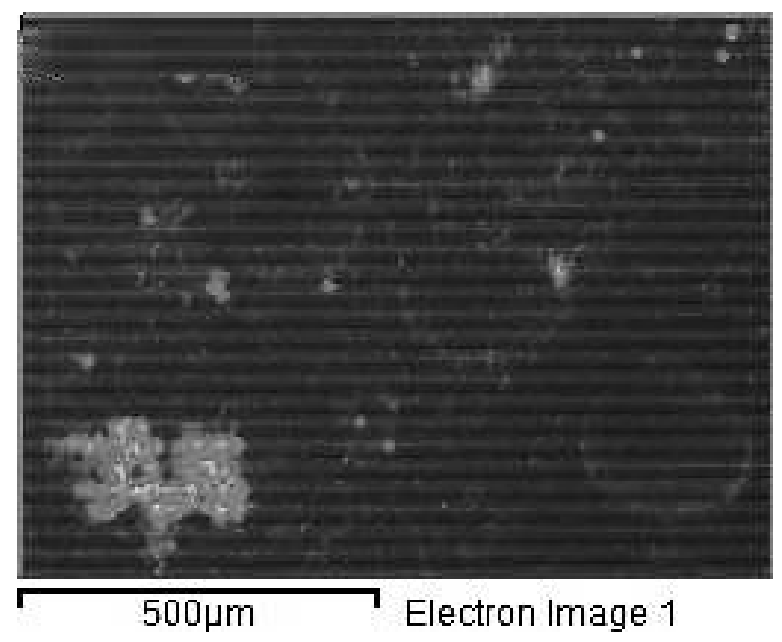

Figure 6 SEM of Agaricus bisporus-AgNPs

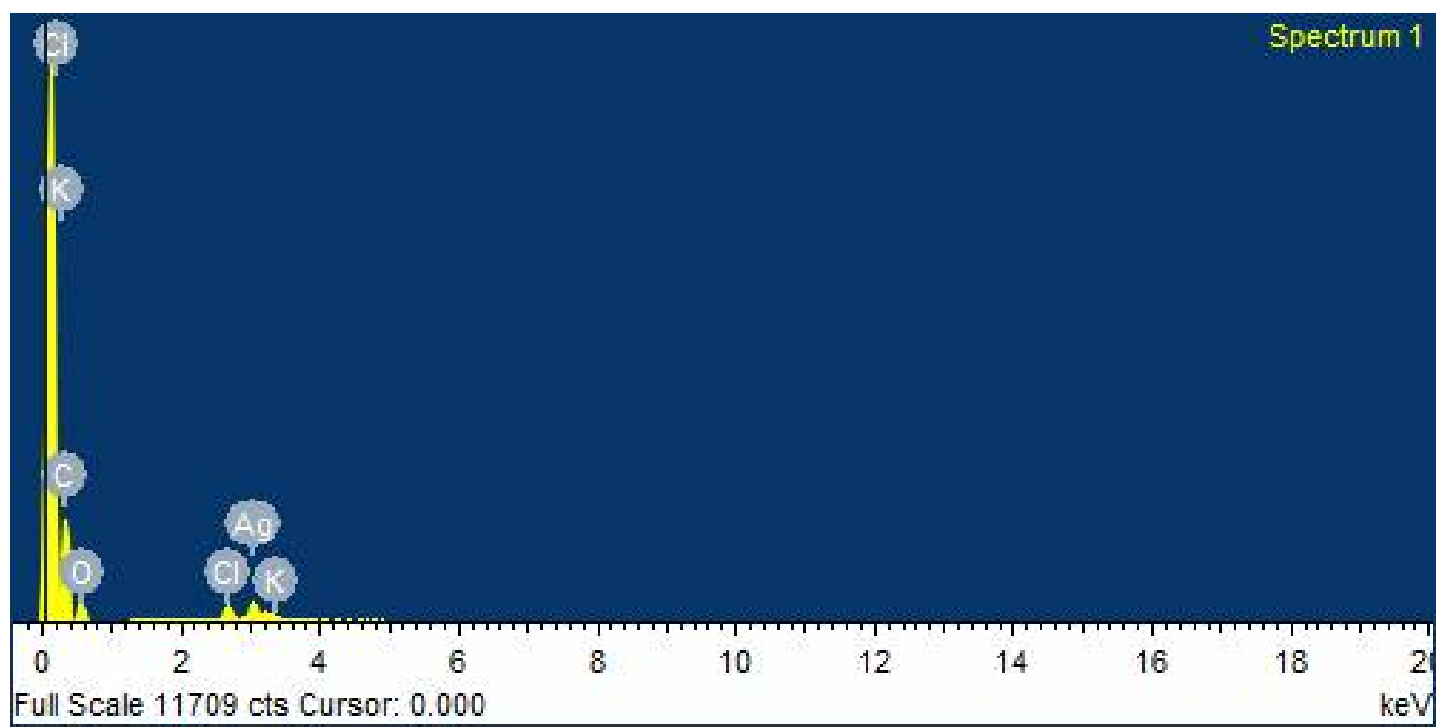

Figure 7 EDS spectrum of AgNPs colloid formed by reaction of $\mathrm{AgNO}_{3}$ with aqueous extract of $A$. bisporus caps 
http://wjst.wu.ac.th

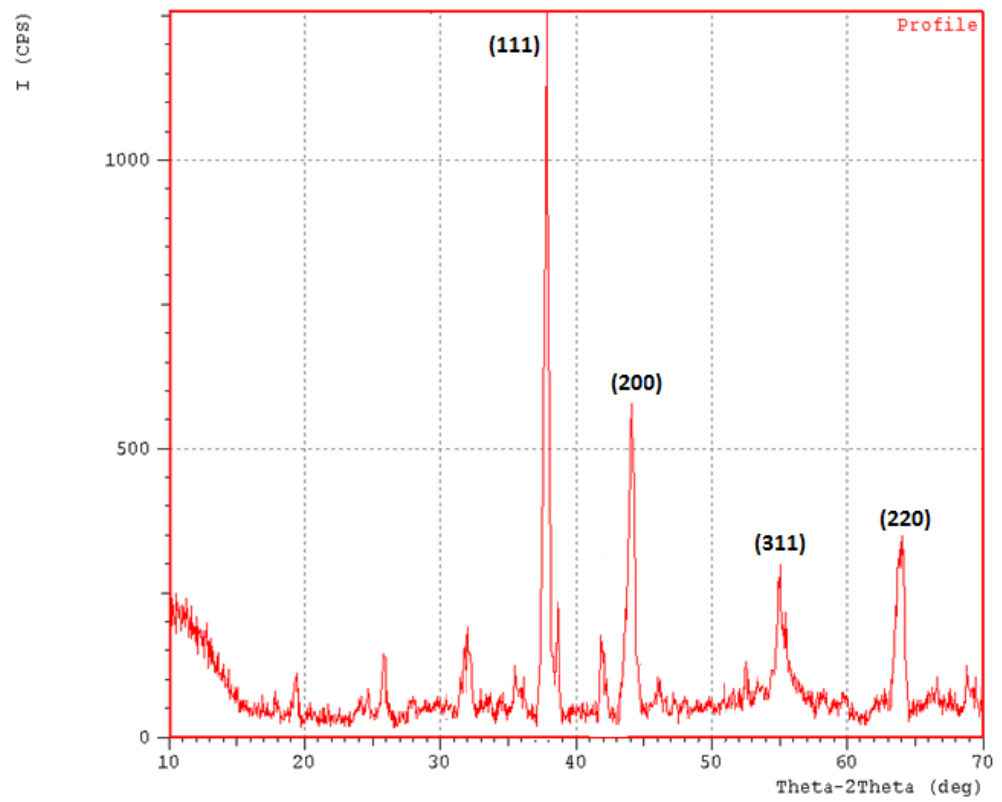

Figure 8 XRD pattern of biosynthesized AgNPs from $A$. bisporus pileus

X-ray diffraction (XRD) measurements can be used to affirm the presence of silver nanoparticles and to estimate their grain size. XRD scan of vacuum dried silver nanoparticles is illustrated in Figure 8. XRD pattern shows that the nanostructures are polycrystalline. The XRD pattern exhibits numerous peaks at $2 \theta$ equal to $38^{\circ}, 44^{\circ}, 55^{\circ}$, and $64^{\circ}$, which can be indexed to the (111), (200), (311), and (220), respectively. Figure 8 reports the formation of face-centered cubic (fcc) AgNPs crystals, which agrees with the values (JCPDS 4-783) [33,34]. The (111) peak has the highest intensity, indicating that (111) is the preferred orientation. The results show that the mean crystallite size of AgNPs is $43.9 \mathrm{~nm}$. This result indicates that the nanocrystalline are domains. The average grain size of the silver nanoparticles can be calculated using the X-ray diffraction peak by Debye-Scherrer Eq. (2) [35];

$\mathrm{D}=\mathrm{k} \lambda / \beta \cos 2 \theta$,

where $\mathrm{D}$ is the average thickness of the crystal grains perpendicular to the crystal plane (nm), $\mathrm{K}$ is the Scherrer constant equal to (0.89), $\beta$ is the Full Width Half Maximum (FWHM), $\lambda$ is an X-ray wavelength ( $\mathrm{CuK} \alpha$ source) of $0.15418 \mathrm{~nm}$, and $\theta$ is the diffraction angle, reflected at $2 \theta=38^{\circ}, 44^{\circ}, 55^{\circ}$, and $64^{\circ}$. The average particle size of the grains is $22.8 \mathrm{~nm}$, which is $41.5 \mathrm{~nm}, 16.9 \mathrm{~nm}, 17.7 \mathrm{~nm}$, and $15.4 \mathrm{~nm}$, respectively.

\section{Anticancer activity of AgNPs}

In Figure 9, the concentration $75 \%$ AgNPs shows that inhibition growth of L20B reached $20.5 \%$ and the concentration of $100 \%$ gave inhibition growth of $35.3 \%$, while the concentration of $50 \%$ did not inhibit L20B cells, transgenic mouse cells line, which expresses the human poliovirus receptor on the surface (CD155). Also, the crude extract of mushroom caps did not exhibit any inhibitory effect in this experiment compared with silver nanoparticles in low concentrations. The cytotoxicity of AgNPs depends on the sizes of nanoparticles and the type of cells [36]. The green AgNPs possess good anticancer activity due to the decrease in the viability percentage of L20B cell line [37]. AgNPs have anticancer activity and are commonly because of their stability characteristics [32,38,39]. FTIR spectrum (Figure 5) shows the capped polysaccharides and polyphenols, and AgNPs play a useful role in treating tumors due to their 
http://wjst.wu.ac.th

antioxidant role and stability, as mentioned by [40]. Cellular uptake of AgNPs conduces the generation of ROS (reactive oxygen species), which irritate oxidative stress. In human body cells, the nanoparticles easily cross the cellular membrane, then the nuclear membrane, and interact with intracellular macromolecules, such as proteins and nucleic acid, with an unknown mechanism [41], in addition to their inhibitory role toward bacterial pathogens [42]. Via gene expression regulation, AgNPs induce apoptosis to target tumor cells without the induction of inflammatory response [40].

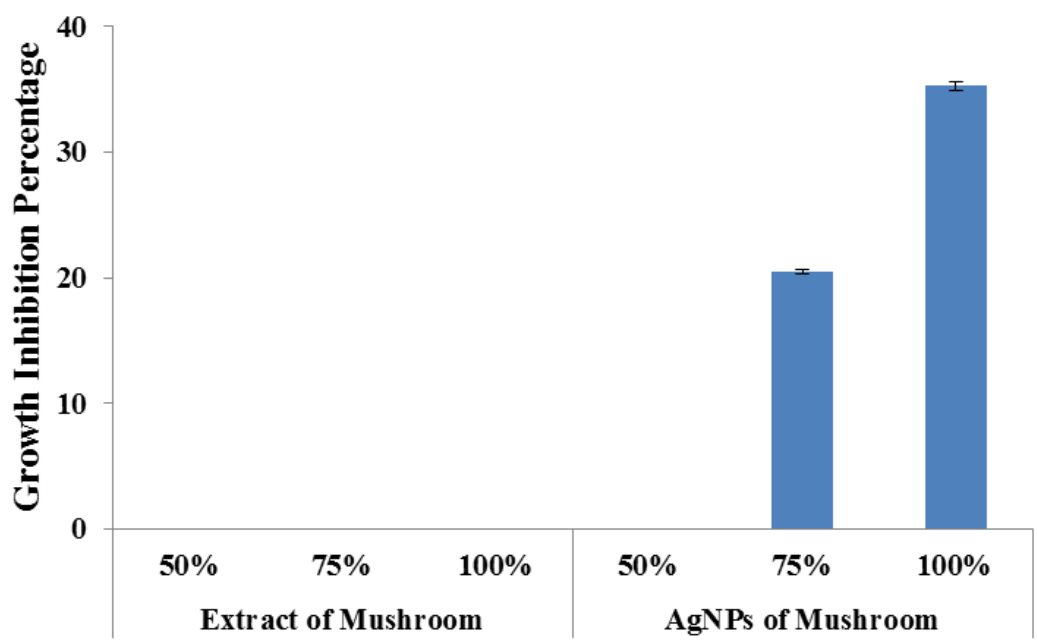

Figure 9 Antitumor activity of $A$. bisporus caps extract and its AgNPs against L20B cell line

\section{Conclusions}

Agaricus bisporus-mediated synthesis of AgNPs was characterized using changing the color solution, UV-Visible spectroscopy, SEM, AFM, SPM, FTIR spectrum, XRD, and EDS analyses. The UV-Visible spectrum exhibits the absorption peak at $418 \mathrm{~nm}$ and is an indicator for the formation of silver nanoparticles. The FTIR spectra exhibited the functional groups of amino acids, polysaccharides, and polyphenols, which joined and interacted with silver ions and act as the reducing and capping agents to the biosynthesized Ag nanoparticles. SEM and EDS refer to the formation of AgNPs with irregular or spherical shapes. The XRD pattern exhibits face-centered cubic (fcc) silver nanocrystals with a size of crystalline AgNPs of $43.9 \mathrm{~nm}$. The biosynthesized AgNPs play a suitable role against mouse cell line, which has receptors for polioviruses (L20B). Roughness average of the biosynthesized AgNPs from $A$. bisporus caps is $15.4 \mathrm{~nm}$, but the roughness is increased after UV irradiation for $1 \mathrm{~h}$ to average $33.6 \mathrm{~nm}$. Histograms of particle size distribution of AgNPs show that the average of AgNPs is $103.57 \mathrm{~nm}$, while the size of nanoparticles reaches $69.47 \mathrm{~nm}$ after exposure to UV radiation of $256 \mathrm{~nm}$. The use of UV radiation leads to enhanced characteristics of silver nanoparticles.

\section{Acknowledgements}

The authors thank the staff of the Department of Biophysics, College of Applied Sciences-Hit, in the University of Anbar, for assisting with this project No. 1/11 on 18 Oct 2017. Other thanks to Prof. Dr. Abdul-Hamid Al-Samurai, the University of Baghdad, for his contribution in taking AFM images.

\section{References}

[1] T Vo-Dinh. Protein Nanotechnology, Protocols, Instrumentation, and Applications. Humana Press, Totowa, NJ, 2005. p. 1-7.

[2] A Gade, A Ingle, C Whiteley and M Rai. Mycogenic metal nanoparticles: Progress and applications. 
http://wjst.wu.ac.th

Biotechnol. Lett. 2010; 32, 593-600.

[3] KW Lem, A Choudhury, AA Lakhani, P Kuyate, JR Haw, DS Lee, Z Iqbal and CJ Brumlik. Use of nanosilver in consumer products. Recent Pat. Nanotechnol. 2012; 6, 60-72.

[4] SK Srikar, DD Giri, DB Pal, PK Mishra and SN Upadhyay. Green synthesis of silver nanoparticles: A review. Green Sustain. Chem. 2016; 6, 34-56.

[5] S Farhadi, B Ajerloo and A Mohammadi. Green biosynthesis of spherical silver nanoparticles by using date palm (Phoenix dactylifera) fruit extract and study of their antibacterial and catalytic activities. Acta Chim. Slov. 2017; 64, 129-43.

[6] B Kumar, L Cumbal and A Debut. Phycosynthesis of silver nanoparticles using Calothrix algae through ultrasonic method. In: Proceedings of the XI Congreso de Ciencia Y Tecnologia ESPE. Sangolqui, Ecuador, 2016. p. 213-6.

[7] AM Abdel-Hadi, MF Awad, NF Abo-Dahab and MF ElKady. Extracellular synthesis of silver nanoparticles by aspergillus terreus: Biosynthesis, characterization and biological activity. Biosci. Biotechnol. Res. Asia 2015; 11, 1179-86.

[8] C Malarkodi, S Rajeshkumar, K Paulkumar, G Gnanajobitha, M Vanaja and G Annadurai. Bacterial synthesis of silver nanoparticles by using optimized biomass growth of Bacillus sp. Nanosci. Nanotechnol. An. Int. J. 2013; 3, 26-32.

[9] A Jaganathan, K Murugan, C Panneerselvam, P Madhiyazhagan, D Dinesh, C Vadivalagan, A Thabiani, B Chandramohan, U Suresh, R Rajaganesh, J Subramaniam, M Nicoletti, A Higuchi, AA Alarfaj, MA Munusamy and S Kumar. Parasitology international earthworm-mediated synthesis of silver nanoparticles: A potent tool against hepatocellular carcinoma, Plasmodium falciparum parasites and malaria mosquitoes. Parasitol. Int. 2016; 65, 276-84.

[10] MN Owaid and IJ Ibraheem. Mycosynthesis of nanoparticles using edible and medicinal mushrooms. Eur. J. Nanomed. 2017; 9, 5-23.

[11] F Atila, MN Owaid and MA Shariati. The nutritional and medical benefits of Agaricus bisporus: A review. J. Microbiol. Biotechnol. Food Sci. 2017; 7, 281-6.

[12] FAO. Food and Agriculture Organization of the United Nations. 2016.

[13] D Rodrigues, AC Freitas, L Pereira, TAP Rocha-Santos, MR Vasconcelos, LM Rodriguez-Alcala, TAP Rocha-Santos, MR Vasconcelos, LM Rodriguez-Alcala, AMP Gomes and AC Duarte. Chemical composition of red, brown and green macroalgae from Buarcos bay in Central West Coast of Portugal. Food Chem. 2015; 183, 197-207.

[14] MN Owaid, A Barish and MA Shariati. Cultivation of Agaricus bisporus (button mushroom) and its usages in the biosynthesis of nanoparticles. Open Agr. 2017; 2, 537-43.

[15] T Sudhakar, A Nanda, SG Babu, S Janani, MD Evans and TK Markose. Synthesis of silver nanoparticles from edible mushroom and its antimicrobial activity against human pathogens. Int. J. PharmTech Res. 2014; 6, 1718-23.

[16] EA Loshchinina, EP Vetchinkina, MA Kupryashina, VF Kursky and VE Nikitina. Nanoparticles synthesis by Agaricus soil basidiomycetes. J. Biosci. Bioeng. 2018; 126, 44-52.

[17] US Senapati, DK Jha and D Sarkar. Structural, optical, thermal and electrical properties of fungus guided biosynthesized zinc sulphide nanoparticles. Res. J. Chem. Sci. 2015; 5, 33-40.

[18] MN Owaid, J Raman, H Lakshmanan, SSS Al-Saeedi, V Sabaratnam and AI Ali. Mycosynthesis of silver nanoparticles by Pleurotus cornucopiae var. citrinopileatus and its inhibitory effects against Candida sp. Mater. Lett. 2015; 153, 186-90.

[19] PL Chih, JT Wei, LL Yuang and CK Yuh. The extracts from nelumbonucifera suppress cell cycle progression, cytokine genes expression, and cell proliferation in human peripheral blood mononuclear cells. Life Sci. 2004; 75, 699-716.

[20] RI Freshney. Culture of Animal Cell. $6^{\text {th }}$ eds. Wily-Liss, New York, 2012.

[21] SS Shankar, A Ahmad and M Sastry. Geranium leaf assisted biosynthesis of silver nanoparticles. Biotechnol. Prog. 2003; 19, 1627-31.

[22] EG Goh, X Xu and PG McCormick. Effect of particle size on the UV absorbance of zinc oxide nanoparticles. Scr. Mater. 2014; 78-79, 49-52.

[23] RP Chahal, S Mahendia, AK Tomar and S Kumar. Effect of ultraviolet irradiation on the optical and 
http://wjst.wu.ac.th

structural characteristics of in-situ prepared PVP-Ag. Dig. J. Nanomater. Biostruct. 2011; 6, 299306.

[24] J Zheng, JD Clogston, AK Patri, MA Dobrovolskaia and SE McNeil. Sterilization of silver nanoparticles using standard gamma irradiation procedure affects particle integrity and biocompatibility. J. Nanomed. Nanotechnol. 2011; S5, 1-6.

[25] R Silverstein, F Webster and D Kiemle. Spectrometric Identification of Organic Compounds. $7^{\text {th }}$ eds. John Wiley and Sons, London, UK, 2005, p. 72-126.

[26] BD Mistry. A Handbook of Spectroscopic Data CHEMISTRY (UV, JR, PMR, JJCNMR and Mass Spectroscopy). $2009^{\text {th }}$ eds. Oxford Book Company, UK, 2009, p. 26-56.

[27] LD Field, S Sternhell and JR Kalman. Organic Structures from Spectra. $4^{\text {th }}$ eds. John Wiley and Sons, UK, 2008, p. 15-20.

[28] K Nakamoto. Infrared and Raman Spectra of Inorganic and Coordination Compounds Part A: Theory and Applications in Inorganic Chemistry. $6^{\text {th }}$ eds. John Wiley and Sons, UK, 2009, p. 1-13.

[29] J Simek. Organic Chemistry. $8^{\text {th }}$ eds. Pearson Education, 2013, p. 412-4.

[30] OH Abid, HM Tawfeeq and RF Muslim. Synthesis and characterization of novel 1,3-oxazepin$5(1 \mathrm{H})$-one derivatives via reaction of imine compounds with isobenzofuran-1(3H)-one. Acta Pharm. Sci. 2017; 55, 43-55.

[31] S Sujatha, S Tamilselvi, K Subha and A Panneerselvam. Studies on biosynthesis of silver nanoparticles using mushroom and its antibacterial activities. Int. J. Curr. Microbiol. App. Sci. 2013; 2, 605-14.

[32] V Kathiravan, S Ravi and S Ashokkumar. Synthesis of silver nanoparticles from Melia dubia leaf extract and their in vitro anticancer activity. Spectrochim Acta Part A Mol. Biomol. Spectrosc. 2014; 130, 116-21.

[33] HA Abod, I Bander and SS Zain-Al-Abddeen. The effect of silver nanoparticles prepared using Aspergillus niger in some pathogenic bacteria Aspergillus niger. Kirkuk Univ. J. Sci. Stud. 2017; 12, $1-16$.

[34] M Ghareib, M Abu, M Mostafa and WE Abdallah. Rapid extracellular biosynthesis of silver nanoparticles by Cunninghamella phaeospora culture supernatant. Iran J. Pharm. Res. 2016; 15, 915-24.

[35] K Abdelrahim, S Younis, A Mohamed, K Salmeen, AEMA Mustafa and S Moussa. Extracellular biosynthesis of silver nanoparticles using Rhizopus stolonifer. Saudi. J. Biol. Sci. 2017; 24, 208-16.

[36] MVDZ Park, AM Neigh and JP Vermeulen. The effect of particle size on the cytotoxicity, inflammation, developmental toxicity and genotoxicity of silver nanoparticles. Biomaterials 2011; 32, 9810-7.

[37] KS Siddiqi, A Husen and RAK Rao. A review on biosynthesis of silver nanoparticles and their biocidal properties. J. Nanobiotechnol. 2018; 16, 14.

[38] S Kummara, MB Patil and T Uriah. Synthesis, characterization, biocompatible and anticancer activity of green and chemically synthesized silver nanoparticles: A comparative study. Biomed. Pharmacother. 2016; 84, 10-21.

[39] HM Abd-Enaby, GM Abo-Elala, UM Abdel-Raouf and MM Hamed. Antibacterial and anticancer activity of extracellular synthesized silver nanoparticles from marine Streptomyces rochei MHM13. Egypt. J. Aquat. Res. 2016; 42, 301-12.

[40] NM El-Deeb, IM El-Sherbiny, MR El-Aassara and EE Hafez. Novel trend in colon cancer therapy using silver nanoparticles synthesized by honey bee. J. Nanomed. Nanotechnol. 2015; 6, 265.

[41] MA Franco-Molina, E Mendoza-Gamboa, CA Sierra-Rivera, RA Gómez-Flores, P ZapataBenavides, P Castillo-Tello, JM Alcocer-González, DF Miranda-Hernández, RS Tamez-Guerra and C Rodríguez-Padilla. Antitumor activity of colloidal silver on MCF-7 human breast cancer cells. Padilla J. Exp. Clin. Cancer Res. 2010; 29, 148.

[42] MN Owaid, R Muslim and HA Hamad. Mycosynthesis of silver nanoparticles using Terminia sp. desert truffle, pezizaceae, and their antibacterial activity. Jordan J. Biol. Sci. 2018; 11, 401-5. 